\title{
Medio Oriente: inestabilidad y crisis del orden regional
}

\section{Middle East: Instability and Crisis of the Regional Order}

\author{
ENRIQUE BALTAR RODRÍGUEZ \\ Universidad de Quintana Roo, México
}

Resumen: En las últimas dos décadas, la situación de la seguridad y la estabilidad política en Medio Oriente ha sufrido un grave deterioro que contrasta con la importancia estratégica de la región como motor energético de la economía mundial. El objetivo del presente artículo es aportar un enfoque interpretativo general que contribuya a la explicación de esa contradictoria evolución a partir del análisis de un conjunto de factores exógenos y endógenos que han ejercido de manera primordial, aunque no limitativa, un efecto perturbador sobre el orden regional desde finales del siglo xx y que ayudan a entender las causas del caos geopolítico en que parece inmerso el Medio Oriente en los albores del presente siglo. Oriente.

Palabras clave: crisis; seguridad; conflicto; geopolítica; Medio

Recepción: 31 de mayo de 2020. / Aceptación: 14 de septiembre de 2020.

D.R. ${ }^{\odot}$ 2021. Estudios de Asia y África Licencia Creative Commons Atribución-NoComercial-SinDerivar (CC BY-NC-ND) 4.0 Internacional 
Abstract: In the last two decades, the security situation and political stability in the Middle East has significantly worsened, in contrast with its strategic importance as the global economy's energy engine. This article offers a general interpretative perspective to help explain this contradictory evolution from the analysis of a set of exogenous and endogenous factors that have exerted a fundamental, although not limiting, effect on the regional order since the end of the last century, and to elucidate the causes of the Middle East's apparent geopolitical chaos at the dawn of this century.

Keywords: crisis; security; conflict; geopolitics; Middle East.

\section{Introducción}

El panorama contemporáneo de Medio Oriente refleja el grave deterioro del orden regional en los inicios del siglo XxI. Después de los atentados terroristas del 11 de septiembre, el curso de la evolución regional siguió una especie de parábola del caos, en la que el escenario de llegada parece más volátil que el de partida. Nuevas e interminables guerras en Iraq, Siria, Yemen y Libia se combinaron con la reactivación de viejos conflictos no resueltos en Palestina y Afganistán, lo que agravó la situación de la seguridad y la dimensión de las tragedias humanitarias que han reafirmado a Medio Oriente como el principal centro expulsor de personas a causa de conflictos armados (ACNUR 2019, 140-141).

Pese a los cuantiosos recursos destinados a la guerra contra el terrorismo, y a las intenciones de promover la democratización en la región, el panorama político de Medio Oriente sigue seriamente comprometido por el juego geopolítico de actores globales y regionales, por la beligerancia de la corriente yihadista y del sectarismo etnorreligioso, y por la vocación represiva de gobiernos autoritarios con una persistente capacidad de renovación. Al Qaeda, símbolo del extremismo violento, no sólo sobrevivió al embate de una imponente cruzada militar, sino que mantuvo una presencia significativa en todos los escenarios regionales de conflicto y logró extender su influen- 
cia a otras zonas del sur de Asia y África subsahariana. Peor aún, el repunte del islamismo radical engendró un fenómeno bicéfalo con el surgimiento y la expansión del Estado Islámico (ISI), devenido en contrincante doctrinal de Al Qaeda por el liderazgo yihadista a escala regional y global.

El deterioro de la seguridad contrasta, sin embargo, con la importancia estratégica que mantiene Medio Oriente para el funcionamiento de la economía global. En 2018, el consumo mundial de energía creció 2.9\%, el más alto desde 2010, y más de la mitad de su producción provino del petróleo (33.6\%) y del gas natural (23.9\%) (вР World Energy 2019, 2). Medio Oriente contribuyó con $33.5 \%$ de la producción mundial de petróleo y con $17.8 \%$ de la de gas natural; y si incluimos a los países árabes del norte de África, la participación total fue de 37 y 22\% en cada caso $(16,33)$. Además de principal productora, y gracias a un bajo consumo energético de apenas $9 \%$ del total mundial, la región también es la mayor exportadora de hidrocarburos, con más de $35 \%$ de los flujos globales; asimismo, en su entorno están enclavados cuatro de los siete estratégicos chokepoints (estrecho de Ormuz, canal de Suez y Sumed, Bab el-Mandeb, y los estrechos turcos) por donde circulan diariamente más de 30 millones de barriles de petróleo con destino a diversas partes del mundo (EIA 2017, 2). Aún más relevante es el potencial para sostener a futuro su función de motor energético de la economía mundial. La región del golfo Arábigo-Pérsico posee 48.3\% de las reservas mundiales probadas de petróleo y $38.4 \%$ de las reservas de gas natural, participación que sube a 52 y $42.4 \%$ con la adición de los países árabes norafricanos (BP World Energy 2019, 14, 30). Casi 72\% del monto regional -equivalente a $34.7 \%$ de las reservas mundiales- está concentrado en Arabia Saudí (17.2\%), Irán (9.0\%) e Iraq (8.5\%), tres países que han rivalizado por el liderazgo regional durante las últimas cuatro décadas.

En virtud de su importancia estratégica, Medio Oriente ha sido escenario de un fuerte incremento de la presencia militar directa de Estados Unidos desde finales del siglo xx, primero a 
raíz de la guerra del Golfo de 1991, y después como resultado de la agresión a Iraq en 2003. En 2018, el Comando Central de Estados Unidos (Centcom), encargado de cubrir la seguridad en un espacio geográfico (territorial y marítimo) que abarca 20 países de Medio Oriente y Asia centro-meridional, aún tenía desplegados más de 50000 soldados en 27 bases e instalaciones militares, distribuidas en 12 países enclavados en el entorno de la península arábiga (Wallin 2018).

El contraste entre el alto valor estratégico y el creciente deterioro de la seguridad encierra una interesante contradicción que amerita un ejercicio explicativo para tratar de identificar las fuentes promotoras de la erosión del orden regional en las últimas tres décadas. Con ese propósito, abordo a continuación algunos factores que, sin pretensiones limitativas, considero esenciales para entender las causas del complejo panorama geopolítico de Medio Oriente en los albores del presente siglo.

\section{Intervencionismo militar, presiones democratizadoras y ruptura de equilibrios}

Desde finales del siglo xx, la estabilidad de Medio Oriente tuvo que encarar los desafíos generados por las secuelas de intervenciones militares destinadas, en principio, a promover cambios en el escenario político regional, pero que terminaron subvirtiendo los equilibrios preexistentes sin lograr asegurar las condiciones para un reordenamiento efectivo sobre nuevas bases. La guerra del Golfo (1991) trajo la implantación hegemónica de Estados Unidos en la zona, y con ella se profundizó la ruptura de la unidad islámica y cobró fuerza la beligerancia del islamismo radical, enfrascado desde entonces en una nueva yihad global contra Occidente que encontró su santuario primero en Sudán, bajo los auspicios de Hasan al-Turabi y Omar al-Bashir, y luego en el Afganistán talibán (Bodansky 2001, cap. 2). Los procesos de Madrid y Oslo, concebidos como la otra cara de la pax americana, fracasaron a su vez en el 
propósito de construir una paz justa y duradera en la región. Después de casi una década de trayectoria zigzagueante, con reiterados estancamientos y retrocesos, las negociaciones para la creación de un Estado palestino desembocaron en una profunda crisis tras la fallida Cumbre de Camp David y el estallido de la segunda intifada a finales de 2000.

La guerra contra el terrorismo, declarada por la administración de George W. Bush después de los atentados del 11 de septiembre, potenció en varios sentidos los riesgos a la estabilidad regional. Desde la década anterior venía cobrando fuerza en los medios académico y político de Estados Unidos una corriente neoconservadora que consideraba el proceso de Oslo como una trampa para la seguridad de Israel. Su visión simpatizaba con la línea dura del Likud y promovía la idea de un realismo ofensivo para resolver la cuestión iraquí, en tanto que veía el derrocamiento de Sadam Husein como una premisa necesaria para romper el rechazo árabe a Israel (Kepel 2004, 25).

Los sucesos del 11 de septiembre convirtieron esa corriente neoconservadora, con exponentes en puestos claves de la nueva administración, en la línea política dominante de la Casa Blanca. La postura de Estados Unidos cambió del arbitraje tolerante propio del proceso de Oslo, al respaldo abierto a la estrategia del gobierno de Ariel Sharon, dirigida a destruir cualquier vestigio de los acuerdos de paz. La nueva doctrina preventiva facilitó la tarea de presentar la intifada como una expresión del terrorismo y legitimó la respuesta represiva de Israel, que responsabilizó de la violencia al grupo Fatah y a su líder Yasir Arafat, con lo que aseguró la invisibilidad de los otrora interlocutores palestinos. La violencia se hizo incontrolable y las agrupaciones islamistas contrarias a la negociación con Israel acrecentaron su influencia, lo que reforzó, paradójicamente, la narrativa oficial de la guerra contra el terrorismo. La violencia frustró la posibilidad de rescatar el proceso de paz, a la vez que se erigió en un formidable obstáculo en el plan estadounidense de remodelar la cuestión palestina mediante la imposición de un mapa de ruta que, en lugar de promover la creación de un Es- 
tado palestino débil y dependiente, reforzó la potencialidad de los territorios ocupados como caja de Pandora para la seguridad regional.

Las campañas militares de Estados Unidos en Afganistán (2001) e Iraq (2003) pusieron igualmente de relieve la inviabilidad del uso de la fuerza como instrumento efectivo de remodelación política (Gordon, Doran y Alterman 2019, 6). En ambos casos, la disimetría militar facilitó la rápida caída del orden autoritario y la imposición de una hoja de ruta para impulsar la transición democrática sobre bases procedimentales: autoridad de transición, asambleas constituyentes, ley de partidos políticos, celebración de elecciones libres y democráticas, etc. Sin embargo, ese ejercicio de nation-building fracasó estrepitosamente al menos en tres aspectos importantes y vinculados entre sí. Primero, las transiciones impuestas allanaron poco el camino a la gobernabilidad y la estabilidad política porque fueron percibidas como implantaciones foráneas y tuvieron que enfrentar el doble embate de los intereses tradicionales, amenazados por los cambios, y de las nuevas fuerzas liberadas tras el descalabro del viejo régimen. En consecuencia, la vulnerabilidad de la transición democrática en ambos países muy pronto quedó al desnudo ante los efectos de la violencia armada, los sectarismos de diverso signo y la corrupción de las nuevas élites gubernamentales, y mostraron una clara incapacidad para ejercer un control efectivo sobre el territorio nacional y sostenerse por sí mismos sin la presencia militar extranjera.

Segundo, el formidable despliegue militar de Estados Unidos también perdió muy pronto su valor disuasivo inicial al verse impelido a librar largas y costosas campañas de pacificación, sobre todo en Iraq. La superioridad militar resultó un recurso incontestable para derrocar regímenes indeseables, pero poco efectiva para neutralizar a grupos insurgentes en un enfrentamiento asimétrico. En vez de convertirse en ejemplos de la remodelación democrática regional, Afganistán e Iraq devinieron en escenarios de conflicto y en símbolos de la lucha 
contra la hegemonía estadounidense que estimularon la movilización de las fuerzas islamistas a escala regional. El fracaso del efecto disuasivo coadyuvó también a configurar un contexto geopolítico un tanto diferente al esperado en principio por la Casa Blanca, en el que países como Irán y Siria quedarían aislados y bajo la presión de la gran fuerza militar desplegada en Iraq. En cambio, el empantanamiento militar no sólo impidió el intento de meter al redil a Irán y Siria, sino que también les proporcionó la oportunidad de ejercer presión e influencia sobre el escenario iraquí a través de sus fronteras, de tal suerte que el potencial de daños colaterales y consecuencias no deseadas determinó que las intervenciones militares generaran más amenazas a la seguridad que las que originariamente estaban destinadas a neutralizar (Jett 2011, 82).

Tercero, la prolongada ocupación militar terminó desacreditando los ideales democráticos que supuestamente defendía, lo que paradójicamente contribuyó a posicionar, incluso en la percepción social, a las fuerzas opuestas a los intereses de Estados Unidos y más alejadas de su ideal democrático. A partir de 2002, las iniciativas de la administración Bush para promover la democracia presionaron a muchos regímenes a entrar en el juego de las reformas políticas y la celebración de procesos electorales (Battaloglu y Farasin 2017, 304-305). En los tres años que siguieron a la invasión de Iraq se realizaron comicios en varios países de la región y la mayoría reflejó la misma tendencia al empoderamiento de las agrupaciones islamistas (Freeman 2014, 62).

En las elecciones legislativas y provinciales de Pakistán, celebradas a finales de 2003, la coalición islamista Muttahida Mahaz-e-Amal (MMA) logró un éxito inesperado que la convirtió en la segunda fuerza de la Asamblea Nacional y le permitió conseguir los gobiernos provinciales en Beluchistán y la Frontera Noroeste, con lo que todo el territorio fronterizo con Afganistán quedó controlado por una corriente islamista radical partidaria de la sharía (ley islámica), el apoyo al talibán y la yihad en Afganistán y Cachemira. En las elecciones legislativas 
(2004) y presidenciales (2005) en Irán, la línea más dura y conservadora de la revolución islámica se impuso sobre la corriente reformista que había prevalecido en los últimos años, lo que permitió la llegada al poder de Mahmud Ahmadineyad, decidido partidario del programa nuclear y con una actitud desafiante hacia Estados Unidos, Israel y las monarquías árabes del Golfo. En el propio Iraq, la Asamblea Constituyente elegida en enero de 2005 para asumir la redacción de la nueva Constitución del país quedó dominada por la Alianza Unida Iraquí, una coalición de agrupaciones chiís de orientación religiosa y proiraní. En Líbano, la alianza antisiria obtuvo la mayor cantidad de escaños en las elecciones legislativas de 2005, pero Hezbolá consiguió la totalidad de los asientos proporcionados por los territorios bajo su influencia. Por último, en enero de 2006, Hamás participó por primera y única vez en las elecciones para el Consejo Legislativo Palestino y consiguió una sorprendente y arrolladora victoria sobre Fatah, la organización hasta entonces políticamente dominante en los territorios ocupados por Israel.

Las intervenciones militares y las presiones democratizadoras que acompañaron la estrategia de guerra contra el terrorismo dejaron un saldo perturbador en la medida en que subvirtieron de varias maneras los viejos equilibrios del orden regional, pero sin lograr los efectos regeneradores necesarios para asegurar la estabilidad sobre nuevas bases (Gordon, Doran y Alterman 2019,5$)$. La brecha resultante contribuyó a la creciente polarización de la arena política y a potenciar la conflictividad debido a la disputa por los espacios de poder. Ese efecto perturbador, derivado del desequilibrio entre destrucción y regeneración, se puso nuevamente de manifiesto en la coyuntura creada por los movimientos de protesta de la llamada Primavera Árabe en 2011.

En sus inicios, la resonancia regional de las protestas generó la ilusión de estar en presencia de una cuarta ola que pondría a Medio Oriente en la cresta de la democratización y barrería los añejos regímenes autoritarios (Abushouk 2016). Los pro- 
blemas estructurales, el desempleo, las desigualdades sociales y la corrupción alimentaron las aspiraciones de cambio en muchos países de la región. Sin embargo, aparte de la caída de algunos connotados dictadores, la confrontación política dejó un saldo bastante desfavorable para la consolidación de una estabilidad sobre bases más democráticas. En países como Libia, Siria y Yemen, las protestas populares desembocaron en largas y cruentas guerras civiles sin que, hasta el presente, se vislumbre una posibilidad de solución política viable. En otros casos, las bases de poder de esos regímenes autocráticos mostraron una fuerte capacidad de resistencia, no sólo para sobrevivir en un contexto de riesgo, sino también para reinventarse en una versión más represiva de autoritarismo (Battaloglu y Farasin 2017, 305).

Los sangrientos conflictos en Libia, Siria y Yemen, agravados por la injerencia geopolítica de actores externos (globales y regionales), contribuyeron a que el ideal democrático volviera a resultar el gran perdedor de la contienda a escala regional. La sociedad civil, que había sido la gran activista del cambio en diversos países, inhibió en buena medida su aspiración reformista por miedo a la inseguridad, a la vez que las élites gobernantes pudieron justificar las acciones represivas de un renovado autoritarismo (Battaloglu y Farasin 2017, 313). Paradójicamente, el reflujo del movimiento democratizador coadyuvó indirectamente a la polarización del panorama político, ya que desde entonces el mayor desafío al statu quo no provino del activismo pacífico de la sociedad civil, sino de las fuerzas antisistema más radicales, lo que acrecentó la espiral de violencia en muchos países de Medio Oriente. En consecuencia, las consideraciones sobre la seguridad, y no la democratización, pasaron a ser el principal problema de preocupación en las percepciones de la sociedad, los gobernantes y la comunidad internacional. 


\section{Carrera armamentista y cambios en la correlación de fuerzas regionales}

El escenario geopolítico de Medio Oriente ha sufrido reacomodos importantes desde finales del siglo xx, debido a la incidencia de factores externos y a la preeminencia conferida por muchos actores regionales a las cuestiones de seguridad y defensa. La guerra del Golfo, la agresión a Iraq y los escenarios de crisis derivados de los fallidos procesos de democratización, entre los eventos más destacables, contribuyeron a una pronunciada militarización de la zona, reflejo de la creciente importancia del ámbito de la seguridad en la política regional. Junto con la presencia militar de Estados Unidos y en asociación con ella, desde el principio de la década de 1990, varios países de la región —-sobre todo las monarquías del Golfo-emprendieron una carrera armamentista para fortalecer sus capacidades militares ante la crisis del panarabismo y la inviabilidad de un sistema regional de seguridad colectiva. A la larga, el incremento sostenido de los gastos militares llevó a Medio Oriente a encabezar las regiones que, en términos porcentuales del PIB, invierten más recursos en el sector de la defensa. En 2018, el gasto militar representó en promedio 5.5\% del PIB regional, una cantidad muy superior a la del resto de las otras zonas geográficas.

La inmensa mayoría de los países de Medio Oriente dedicaron al sector militar un porcentaje del PIB por encima de la media mundial durante las últimas tres décadas (Banco Mundial 2019). En lo que respecta a las monarquías del Golfo, la diferencia es muy significativa, especialmente en el caso de Arabia Saudí. Al cierre de la década de 1990, el gasto militar del reino saudí era ya, en términos brutos, el mayor de la región, con 19964 millones de dólares; sin embargo, en los años siguientes continuó creciendo vertiginosamente hasta triplicarse en 2018, resultado que convirtió a dicho reino en el tercer país con el mayor gasto militar, después de Estados Unidos y China, y en el principal comprador de armas del mundo al acaparar $12 \%$ del monto global de las importaciones (SIPRI 2019, 9). 
El resto de las monarquías del Golfo, aunque en grado menor, siguió la misma tendencia ascendente en sus gastos militares. En 2018, Kuwait y Omán destinaron cada uno al sector militar más dinero que Iraq y más del doble que Egipto (Banco Mundial 2019), las dos viejas potencias militares del mundo árabe durante la Guerra Fría. En los casos de Catar y Emiratos Árabes Unidos (EAU), la tendencia pudiera ser aún mayor, pero la comparación resulta difícil porque no se dispone de datos recientes. El gobierno catarí, reacio a transparentar sus gastos militares, dejó de informar a los organismos internacionales desde 2011, y EAU adoptó la misma postura después de 2014, un problema que, según el SIPRI $(2019,7)$, se ha vuelto una alarmante práctica global. La suposición, no obstante, parece bastante consistente si consideramos que el crecimiento del gasto militar de EAU en el periodo 2000-2014 fue de $387.3 \%$, y que la cifra de 22755 millones de dólares registrada ese último año equivale a 34\% del gasto de Arabia Saudí en 2018 (tercer lugar mundial), y fue ampliamente mayor al de Turquía, Israel e Irán, y más de siete veces el de Egipto (Banco Mundial 2019).

Gasto militar por países en 2018 (USD)

Gasto militar por países en 2018 (USD)

\begin{tabular}{lccrcrrr}
\hline \multicolumn{1}{c}{ País } & $\begin{array}{c}\text { Gasto } \\
\text { total } \\
\text { (millones) }\end{array}$ & $\begin{array}{c}\text { Gastoper Población } \\
\text { cápita }\end{array}$ & $\begin{array}{c}\text { (millones) } \\
\text { (maís }\end{array}$ & $\begin{array}{c}\text { Gasto total } \\
\text { (millones) }\end{array}$ & $\begin{array}{r}\text { Gasto per Población } \\
\text { cápita } \\
\text { (millones) }\end{array}$ \\
\hline A. Saudí & 67555 & 2005 & 33.70 & Egipto & 3110 & 32 & 98.42 \\
EAU & $22755^{*}$ & $2363 *$ & 9.63 & Siria & n.d. & n.d. & 16.90 \\
Omán & 6710 & 1392 & 4.82 & Líbano & 2776 & 428 & 6.48 \\
Kuwait & 7296 & 1767 & 4.13 & Irán & 13194 & 161 & 81.80 \\
Catar & n.d. & n.d. & 2.78 & Israel & 15947 & 1796 & 8.88 \\
Baréin & 1397 & 890 & 1.57 & Turquía & 18967 & 230 & 82.31 \\
Jordania & 1958 & 197 & 9.95 & Yemen & $1715^{*}$ & $60 *$ & 28.49 \\
Iraq & 6318 & 164 & 38.43 & Mundo & $1.74 *$ & 229 & 7594.27 \\
\hline
\end{tabular}

* Cifra de 2014, último año disponible en la serie estadística.

** Billones de dólares.

Fuente: elaboración propia con información del Banco Mundial. 
El indicador del gasto per cápita hace más ostensible la nueva realidad del escenario militar de Medio Oriente en los inicios del siglo XXI. En 2018, el gasto militar per cápita de Arabia Saudí fue de 2005 dólares por habitante, casi 10 veces el promedio del gasto mundial. De acuerdo con el último dato de 2014, el de EAU ya era incluso superior al saudí y rondaba los 2363 dólares por habitante. El gasto per cápita de Kuwait casi octuplicó la media mundial y el de Omán fue seis veces mayor. Hasta el diminuto Baréin estuvo cerca de cuadruplicar el promedio global. En contraste, el gasto militar per cápita del resto de los países árabes fue muy inferior y, con excepción de Líbano, estuvo incluso por debajo de la media mundial. Estos datos ayudan a entender la nueva dinámica en la lucha por la hegemonía regional, caracterizada por el ocaso de los viejos liderazgos árabes (Egipto, Iraq, Libia, Siria) y el creciente papel de las monarquías del Golfo encabezadas por Arabia Saudí. La preocupación por la seguridad nacional después de la agresión iraquí a Kuwait y el interés de Estados Unidos por convertir a las ricas monarquías petroleras en clientes preferentes de su complejo militar industrial se combinaron para que los otrora débiles países del Golfo entraran en un fuerte proceso de fortalecimiento y modernización de sus fuerzas armadas. Como resultado, el nuevo potencial militar vino a complementar su ya importante influencia económica e ideológica, y les ofreció mayores capacidades y posibilidades para intervenir activamente en la geopolítica y en los escenarios de conflicto en la región.

El único país con un gasto militar per cápita a la altura de las monarquías del Golfo es Israel, sin duda la gran potencia militar de la región y para la cual la seguridad nacional ha sido la principal prioridad desde su creación en 1948. A diferencia de sus vecinos árabes, Israel cuenta con arsenales nucleares y una moderna industria bélica que le ha permitido ubicarse actualmente en el octavo lugar mundial de los exportadores de armamento (SIPRI 2018, 8).

Otro caso que conviene matizar es el de Irán, debido a que los discretos indicadores del gasto militar no reflejan los 
esfuerzos del gobierno de Teherán por desarrollar una producción nacional de armamentos. Mientras que las monarquías del Golfo son fuertes importadoras de tecnología militar, sobre todo estadounidense, el prolongado aislamiento internacional y las sanciones impuestas a la revolución islámica obligaron a Irán a buscar alternativas más autárquicas. El controvertido programa nuclear iraní constituye el símbolo más relevante de ese esfuerzo. Durante los dos periodos de gobierno de Mahmud Ahmadineyad (2005-2013) fue motivo de fuertes tensiones internacionales, que luego bajaron de tono gracias a las negociaciones que cristalizaron en el acuerdo multilateral de 2015, mediante el cual el programa nuclear iraní quedó sujeto a supervisión internacional para asegurar su uso con fines exclusivamente pacíficos, a cambio del levantamiento del régimen de sanciones internacionales impuesto al país.

Las tensiones se reactivaron con la llegada a la Casa Blanca del presidente Donald Trump y la adopción de una línea dura frente a Irán que llevó a la salida unilateral de Estados Unidos del acuerdo en 2018 y al regreso a una política de sanciones que, como en el pasado, parece mostrar poca efectividad para obligar al gobierno de Teherán a cambiar su política regional (Gordon, Doran y Alterman 2019, 7). Pero el tema nuclear, en todo caso, es sólo la punta del iceberg en el desarrollo de una industria militar capaz de construir unidades navales de superficie, submarinos y aviones de combate, y, sobre todo, de procurarle el mayor y más diversificado arsenal de misiles de Medio Oriente (Bahgat 2019). De acuerdo con el más reciente ranking mundial, las fuerzas armadas de Irán se ubican en el lugar 14 por su potencia de fuego convencional, por delante de Arabia Saudí (17) e incluso de Israel (18) (Global Firepower 2020).

\section{Sectarismo, autoritarismo y geopolítica}

La influencia del sectarismo constituye otro rasgo distintivo del escenario político de Medio Oriente de las últimas dos décadas, 
tanto en el orden interno como en la geopolítica regional. La explicación de ese fenómeno, circunscrito generalmente a la rivalidad sunní-chií, con frecuencia se asocia a las consecuencias de factores internacionales y regionales, como la invasión estadounidense a Iraq, que provocó el desplazamiento de la dominante comunidad sunní y allanó el camino al poder de la mayoría chií, a la vez que contribuyó a incrementar la influencia de Irán a nivel regional; la coyuntura de la Primavera Árabe, en la que las tensiones sectarias cobraron fuerza en diversos países al calor de las protestas populares y de la represión gubernamental; y el papel de los actores externos en la configuración de los alineamientos sectarios en los conflictos armados en Iraq, Libia, Siria y Yemen (Rørbæk 2019, 24).

Esa percepción permite entender la creciente atención conferida a la cuestión del sectarismo en Medio Oriente, sobre todo después de 2003, y la aparición de una importante cantidad de estudios sobre el tema que, independientemente de sus aportaciones específicas, ponen de relieve la variedad de enfoques y la ausencia de una definición consensuada del concepto. El problema de fondo no estriba en la simple negación o reconocimiento de las dinámicas sectarias -y en particular de la sunní-chií- y su papel en las sociedades contemporáneas de Medio Oriente, sino más bien en la discusión del contenido explicativo de un concepto cuyo significado polisémico propende a generar confusión y vaguedad sobre la naturaleza específica del fenómeno al que remite, lo que propicia con frecuencia el contrapunteo de enfoques binarios, por ejemplo entre sectarismo como expresión religiosa o manifestación política, o entre armonía y división/conflicto. De esta suerte, el término sectarismo puede aparecer como sinónimo de identidad sectaria (religiosa, étnica o de otro tipo) o referirse sólo a determinados ámbitos de esa identidad y sus formas particulares de interacción con otros grupos subnacionales, generalmente las de naturaleza conflictiva. El término también puede circunscribirse al ámbito doctrinal (religioso) o a su dimensión política (instrumentalización), y dentro de esta 
última puede remitirnos a los juegos de intereses de las élites sectarias, a una política de gobierno e, incluso, en países como Líbano, a una forma particular de éste. Los críticos más enérgicos del concepto consideran infructuoso el debate en torno a una definición más funcional y proponen descartar su uso, ya que el grado de ambigüedad, el nivel de politización y la carga negativa que el término implica son tales que hacen imposible su salvación (Haddad 2017, 364; 2020, 18-19).

Este apartado no pretende adentrarse en la discusión conceptual, sino más bien destacar la importancia de la identidad sectaria, en especial la sunní-chií, en la política interna y la geopolítica regional. En ese sentido, el análisis asume la perspectiva de Makdisi $(2000,7)$, quien define el sectarismo en términos del "despliegue de la herencia religiosa como un marcador principal de la identidad política moderna". La politización de esa herencia puede expresarse en diversas formas y grados, y fluir en sentido bidireccional, desde abajo (comunidades) o desde arriba (estructuras de poder). Sin embargo, ese proceso no constituye una tendencia invariable y permanente, y tampoco está sujeto a un curso inevitable. Por lo general adquiere sentido en determinadas circunstancias, especialmente en los contextos de crisis, donde el comportamiento ordinario y mundano de las interacciones sectarias puede resultar afectado por la potenciación de las diferencias con fines políticos. La dinámica sunní-chií en las sociedades contemporáneas de Medio Oriente es particularmente multifacética y sus interacciones cotidianas integran un amplio universo de mediaciones sociales que rebasan, las más de las veces, los rígidos límites del dogma religioso. En consecuencia, las identidades sectarias no revisten la misma importancia en todas partes y sus expresiones varían en grados y formas en dependencia del medio urbano o rural que las cobija. Sin embargo, los escenarios de crisis generados tras la invasión a Iraq o la Primavera Árabe estimularon la tendencia a la instrumentalización de la dimensión conflictiva de la interacción sunní-chií como marcador de identidades políticas, instrumento de movilización 
social y estrategia de sobrevivencia de los gobiernos autoritarios (Valbjørn 2019).

Un reciente estudio basado en el análisis estadístico del Ethnic Power Relations Dataset arroja luz sobre el repunte de esa tendencia. La investigación concluye que Medio Oriente es la única región donde la afiliación religiosa (incluida la sectaria) constituye con mucho el marcador de identidad predominante en la determinación de la pertenencia a grupos, y que, en comparación con las personas de otras zonas del mundo, la población tiene en promedio el doble de probabilidades de pertenecer a grupos de identidad excluidos de la representación política legítima (Rørbæk 2019, 23). Esas dos ideas son claves para entender el contexto interno de la propagación del sectarismo como bandera de movilización social en la arena política y como estrategia de los regímenes autoritarios para fortalecer sus bases sociales de apoyo y frustrar con políticas divisorias las aspiraciones de actores políticos con una orientación democrática y nacional.

Después de 2011, sobre todo, el interés de sobrevivencia de las élites dominantes recrudeció la "sectarización" de la política pública. La adscripción sectaria se reforzó en instituciones claves para la preservación del poder, como el ejército y los servicios de inteligencia; en las instituciones de representación política y en el manejo de los distritos electorales. La inequidad en el acceso a los empleos del sector público creció en favor de los miembros de la comunidad políticamente dominante, y lo mismo ocurrió con los beneficios de los servicios públicos y la presencia en los medios de difusión. En países como Baréin y Kuwait, los gobiernos han recurrido a promover la inmigración para modificar la correlación demográfica entre la población sunní y chíi (Valbjørn 2019, 139). De diversas maneras, la narrativa del sectarismo ha sido utilizada por el poder para generar tensiones confesionales entre la población, incluido el uso de recursos mediáticos y el patrocinio gubernamental de agrupaciones civiles encargadas de promover la identidad sectaria. 
Aunque la división sunní-chií constituye su expresión más sobresaliente, la problemática de la identidad política sobre bases sectarias en Medio Oriente es mucho más amplia e involucra también la politización de otros tipos de identidades grupales. En países donde se expresa la rivalidad sunní-chií, la dinámica del sectarismo puede incluir a grupos cuya identidad no se define esencialmente por la dimensión religiosa, como sucede con los kurdos en Iraq y Siria. La política sectaria puede, incluso, estar latente en lugares donde no opera la lógica de esa división. Es el caso de Jordania, con fuertes diferencias entre la relegada población palestino-jordana y la comunidad transjordana beneficiada por la política del régimen; y el de Egipto, donde el sectarismo se alimenta de dos contradicciones particulares: musulmanes versus cristianos coptos, e islamistas versus secularistas (Valbjørn 2019, 142). En ambos casos, los gobiernos presumen actuar como árbitros y garantes de la estabilidad interna, pero en realidad la exacerbación de las diferencias sectarias ha contribuido a la polarización social y política en muchas partes de la región, lo que ha generado divisiones y violencia societal que sirven de justificación a la creciente represión estatal. La renovación del autoritarismo bajo las sombras del sectarismo no sólo parece haber asegurado así su sobrevivencia, sino que, a futuro, podría incluso volverse más resistente a las presiones democratizadoras que en el pasado (Rørbæk 2019, 24).

Por otra parte, el sectarismo representa una dimensión importante de la geopolítica regional. Resulta difícil determinar si la geopolítica sectaria es una consecuencia del repunte del sectarismo interno o viceversa, pero la interdependencia de ambos parece bastante evidente. Desde finales de la década de 1970, la contradicción entre el wahabismo sunní de la monarquía saudí y el radicalismo chií de la revolución iraní cobró una creciente relevancia en el tablero geopolítico regional. Durante el decenio de 1980, Arabia Saudí y otras monarquías del Golfo, amén de sus claras diferencias ideológicas con el régimen secular y panarabista de Iraq, apostaron tácticamente por la 
contención militar de Irán al apoyar a Sadam Husein con cuantiosos recursos durante los ocho años de la guerra iranio-iraquí. Después de la guerra del Golfo, y en particular en las últimas dos décadas, la confrontación se ha tornado más directa y multifacética, en proporción al acrecentamiento de las capacidades de ambos actores, incluida la militar, para contender por la hegemonía regional.

La perspectiva sectaria ha contribuido a configurar un escenario regional relativamente dominado por la rivalidad entre dos ejes geopolíticos: el sunní, liderado por Arabia Saudí e integrado por las otras monarquías del Golfo, Egipto y Jordania; y el chií, compuesto por Irán y su franja de influencia: el Iraq de mayoría chií, el gobierno alauita de Bashar al-Asad en Siria, Hezbolá en Líbano y, más recientemente, los hutíes en Yemen. Las acciones para retener, modificar o expandir las áreas de influencia de ambos ejes sectarios constituyen un factor importante del agravamiento de la inestabilidad regional, toda vez que su injerencia atiza la beligerancia en los escenarios de conflicto y obstaculiza la viabilidad de las soluciones políticas, como ha quedado demostrado en las sangrientas e interminables guerras civiles en Siria y Yemen.

Sin embargo, tampoco conviene exagerar la importancia de los alineamientos sobre tales bases, ya que el universo de la geopolítica regional es mucho más dinámico y pragmático, lo cual favorece la interacción de intereses particulares y divergentes que escapan del molde de la lógica sectaria. Emiratos Árabes Unidos, paradójicamente, fue el segundo socio comercial de Irán durante todo el periodo de sanciones previo al acuerdo nuclear, sólo superado por China, y sostuvo esa posición hasta 2017 (wITs 2018). La crisis relacional entre Arabia Saudí y Catar, resultado de la creciente independencia de la política catarí respecto a la línea de Riad, provocó una profunda fractura del Consejo de Cooperación del Golfo en 2017. Arabia Saudí, EAU y Baréin rompieron relaciones con Catar y le impusieron un boicot económico, al que se sumaron Egipto y Yemen. En cambio, Kuwait y Omán no sólo permanecieron neutrales, 
sino que mantuvieron relaciones cordiales con Irán, en tanto que, a consecuencia del boicot, el gobierno catarí estrechó más sus relaciones con Irán y Turquía.

El tradicional apoyo de Irán a Hamás como parte de su política antiisraelí o sus esfuerzos por normalizar las relaciones con Egipto durante la presidencia de Mohamed Morsi, islamista de la corriente de los Hermanos Musulmanes, tampoco encuadran bien en una lógica sectaria. Un último caso que ilustra la complejidad de la geopolítica regional es el tácito acercamiento entre Arabia Saudí e Israel, abiertamente respaldado por la administración de Donald Trump desde su arribo a la Casa Blanca (Gordon, Doran y Alterman 2019, 15). El temor compartido por la amenaza de Irán, y el interés de concertar esfuerzos para contener su influencia regional, relegaron a un plano secundario las posiciones y los desacuerdos en torno al diferendo palestino-israelí, la causa histórica del mundo árabe.

Durante los últimos nueve años, la guerra civil en Siria ha sido el principal centro gravitacional de esa complejidad geopolítica. Actores globales y regionales con intereses divergentes han tomado partido en el escenario militar y diplomático y han favorecido la prolongación del conflicto y complicado las posibilidades de llegar a una solución política negociada. Desde el inicio de las hostilidades, la decisión de apoyar a Bashar al-Asad o a la oposición estuvo determinada por las motivaciones particulares de los actores foráneos. Rusia e Irán han sido los principales apoyos externos del régimen sirio por razones diferentes. La crisis siria ofreció a Rusia la oportunidad de fortalecer su posición de contrapeso en los asuntos mundiales y de acrecentar su presencia y su prestigio en una región controlada por Estados Unidos desde el final de la Guerra Fría (Allison 2013). En cambio, para Irán, el respaldo al régimen alauita, más que un compromiso sectario de cuestionable valía por el carácter secular del gobierno sirio, representa la defensa de un aliado clave en su estrategia regional y política antiisraelí. 
A pesar del interés compartido por derrocar al régimen sirio, las divergencias políticas, militares y religiosas entre los grupos opositores, así como los intereses de los aliados foráneos, impidieron la integración efectiva de un frente antigubernamental encabezado por la Coalición Nacional para las Fuerzas de la Revolución y la Oposición Siria, ya que en los hechos los actores externos priorizaron sus preferencias dentro del abigarrado espectro político de la oposición. Estados Unidos y sus aliados europeos apostaron por los sectores más moderados y seculares del Ejército Libre Sirio, afectado por una progresiva islamización de sus filas, y que a la postre resultó la alternativa militar más débil. Arabia Saudí optó por canalizar su apoyo hacia los grupos armados islamistas de orientación wahabita, mejores interlocutores para los intereses de Riad, mientras que Catar siguió una línea más amplia que incluyó también el respaldo a la oposición islamista vinculada a los Hermanos Musulmanes.

Israel y Turquía, aliados tradicionales de Estados Unidos en la región, adoptaron posiciones particulares ante el conflicto sirio. Las principales preocupaciones de Israel han sido mantener la actividad militar de Hezbolá y del ejército sirio lejos de sus fronteras y de la región del Golán, así como evitar un mayor posicionamiento de Irán en el vecino país. Pero frente a la cuestión del cambio de gobierno en Siria, la política de Tel Aviv se mostró desde el inicio mucho más cauta, y dio la impresión de preferir el trato con un régimen débil, conocido y ya disuadido, que enfrentar el riesgo de un cambio incierto y caótico (Mesa Delmonte 2017, 276). Por su parte, en la postura de Turquía a lo largo del conflicto ha estado siempre latente la determinación de impedir la autonomía kurda en el norte de Siria y de reforzar la defensa de su frontera (Oztig 2019, 122) apoyando a los grupos rebeldes más afines a sus intereses y atribuyéndose el derecho a realizar incursiones militares contra las fuerzas kurdas e incluso contra las tropas del régimen sirio, acciones que han delineado una compleja y fluctuante relación del gobierno de Erdogan con Estados Unidos y Rusia. 
Tras nueve años de enfrentamientos armados, y con el apoyo de Rusia e Irán, el régimen de Bashar al-Asad ha consolidado su posición militar y ejerce control sobre la mayor parte del territorio del país. Desde 2019, la norteña provincia de Idlib se mantiene como el único bastión importante de la resistencia armada, luego del descalabro de la oposición en las provincias meridionales de Quneitra y Deraa, la derrota territorial del Estado Islámico y la decisión del presidente Trump de retirar los efectivos militares de Siria (Humud y Blanchard 2020). Pese a ello la crisis siria, con un costo estimado de 300000 millones de dólares, 400000 víctimas fatales y 11 millones de refugiados y desplazados internos, no parece vislumbrar una posible solución en el corto plazo.

Aunque muy debilitada, la oposición armada y política sigue activa dentro y fuera del país, y los canales de negociación (Ginebra y Astaná) no muestran avances significativos para concretar un acuerdo de paz duradero. La intervención directa de fuerzas turcas en Idlib es otro factor de riesgo que agrava la situación en la frontera turco-siria y pudiera potenciar las actuales proporciones del escenario militar (Humud, Zanotti y Thomas 2019; Humud y Blanchard 2020, 12-13). La autonomía kurda en la región noreste constituye otro frente abierto donde parece difícil un entendimiento, debido a la intransigencia de Turquía, al respaldo popular y la capacidad militar del proyecto de Rojava, y a las aspiraciones de Bashar al Asad de recuperar el control sobre esa parte del país. Pero aun cuando la vía política pudiera finalmente sortear esos escollos, incluida la incorporación de la cuestión kurda a la agenda de negociaciones, la paz en Siria resultará difícil de lograr mientras persista la beligerancia de los grupos yihadistas asociados con Al Qaeda y el Estado Islámico. 


\section{Influencia del islamismo radical y expansión} de la corriente yihadista

A casi veinte años de los atentados del 11 de septiembre, el islamismo radical representa un peligro mayor que en 2001. Los grupos yihadistas se multiplicaron y sus acciones violentas se extienden por toda la geografía regional con diversos grados de intensidad. De acuerdo con el Country Reports on Terrorism 2017, publicado en septiembre de 2018, de las 61 organizaciones calificadas de terroristas por el Departamento de Estado de Estados Unidos, 28 (46\%) operan en Medio Oriente y Norte de África, de las cuales 17 (28\% del total global y 61\% del total regional) se crearon después del año 2000, y ocho de ellas (28.5\% del total regional) surgieron durante el reflujo de la llamada Primavera Árabe (United States Department of State 2018, 277-279).

Paradójicamente, la corriente islamista radical logró sacar partido de dos coyunturas regionales que parecían destinadas, en principio, a neutralizar su influencia. La guerra contra el terrorismo, y en particular la invasión a Iraq, derivó en un búmeran, toda vez que la opción militar falló en garantizar la estabilidad de la transición política y terminó desencadenando problemas más graves de seguridad. La presencia militar de Estados Unidos, y los sentimientos antinorteamericanos asociados a ella, proporcionaron al islamismo radical una bandera de combate y un efectivo recurso de movilización social que posibilitaron la rápida conversión de la resistencia contra la ocupación estadounidense en Iraq en un nuevo escenario de la yihad regional, como lo fuera Afganistán durante la época de la intervención soviética.

Al Qaeda fue forzada a cambiar de estrategia para soportar la presión de la lucha antiterrorista. Con su centro de mando sometido a un gran asedio militar en la frontera afganopakistaní desde finales de 2001, la organización experimentó una creciente descentralización operativa y comenzó a conciliar sus fines globales con causas específicas y aliados locales, 
lo que a la larga le permitió no sólo sobrevivir sino también acrecentar su influencia - a través de la conformación de células $\mathrm{y}$ franquicias regionales, unidas por el vínculo doctrinal, pero con una amplia autonomía operativa y comprometidas con las causas de sus entornos locales (The Soufan Center 2019, 7). Iraq fue el primer escenario de esa estrategia cuando el grupo insurgente de Abu Musab al-Zarqawi declaró su lealtad a Osama bin-Laden en octubre de 2004. En 2006, el Grupo Salafista para la Predicación y el Combate, agrupación yihadista de origen argelino escindida del Grupo Islámico Armado en 1997, siguió el mismo camino y se transformó en Al Qaeda del Magreb Islámico, y extendió sus operaciones por el norte de África e incluso en algunos países al sur del Sahara. Poco después, en 2009, apareció Al Qaeda en la península arábiga, fruto de la coordinación de grupos yihadistas saudíes y yemeníes.

La segunda coyuntura vino con la llamada Primavera Árabe en 2011. La amplitud de las protestas populares en diversos países de la región generó la ilusión temporal de que la corriente reformista y democrática podía ser capaz de precipitar la caída de los regímenes autoritarios y dejar sin base social de apoyo al islamismo radical. Pero ninguna de las dos expectativas se concretó. En Libia, Siria y Yemen, donde las protestas degeneraron en guerra civil, la corriente yihadista y el sectarismo religioso encontraron un terreno propicio para afianzarse como actores armados dentro de los escenarios de conflicto. En los otros países, el fracaso de la oleada liberal permitió a los grupos islamistas aprovechar en su favor el descontento social causado por la persistencia del autoritarismo y de los problemas económicos que agobiaba a la mayoría de la población, sobre todo a la juvenil. Las condiciones objetivas que poco antes habían desatado un formidable movimiento democrático a escala regional, paradójicamente contribuyeron también a fortalecer las bases de apoyo de las agrupaciones islamistas. Incluso en Túnez, donde la transición democrática mostró más avances y el islamismo radical tenía menos fuerza, la amnistía general proclamada por el nuevo gobierno devolvió a las calles a cerca 
de 2500 islamistas acusados de terrorismo, quienes tuvieron un papel primordial en el repunte del yihadismo después de 2011 (Lounnas 2019, 100-101). La crisis de seguridad generada por las revueltas abrió amplios espacios para la inserción de Al Qaeda en la convulsa dinámica social del mundo árabe. En países como Egipto y Túnez, su presencia tuvo que lidiar con la fuerte influencia política de los Hermanos Musulmanes, de corte más moderado; pero en los escenarios de conflicto armado (Siria, Yemen y Libia) la injerencia de Al Qaeda creció rápidamente.

La estrategia descentralizadora de Al Qaeda también tuvo un contrasentido que contribuyó al surgimiento de su mayor desafío. Para 2010, la rama iraquí de Al Qaeda parecía ya seriamente debilitada por la muerte de sus principales jefes y muchos de sus militantes, pero la retirada militar de Estados Unidos de Iraq y el estallido del conflicto en Siria proporcionaron una gran oportunidad para la revitalización del Estado Islámico de Iraq (ISI) bajo la dirección de su nuevo líder Abu Bakr al-Baghdadi. Desde 2012, el activismo de IsI empezó a ganar fuerza en el norte de Iraq y en Siria, donde bajo su auspicio se constituyó el Frente Al Nusra (Jabhat al-Nusra), cuyo núcleo inicial estuvo compuesto de yihadistas sirios militantes de ISI que regresaron a su país de origen para luchar contra el régimen de Bashar al Asad. Ese origen condujo pronto a una contradicción entre la aspiración autonómica del Frente Al Nusra como rama siria de Al Qaeda y la vocación hegemónica de ISI como centro matriz, la cual cobró más intensidad en 2013 con la decisión del segundo de adoptar el nombre de Estado Islámico de Iraq y el Levante (IIIL), que dejaba entrever la intención de ejercer un liderazgo transfronterizo.

El respaldo otorgado al Frente Al Nusra por el sucesor de Osama bin Laden, el egipcio Ayman al Zawahiri, precipitó la ruptura entre $\mathrm{Al}$ Qaeda y $\mathrm{Abu} \mathrm{Bakr}$ al-Baghdadi, cuya visión además difería abiertamente en dos cuestiones claves de la estrategia yihadista (Fuente 2018, 198-201). En contraste con la visión futurista del proyecto de Al Qaeda, el líder de IsIL 
aspiraba al control territorial para la proclamación inmediata de un califato. Asimismo, era ferviente partidario de la imposición rigurosa y violenta de la sharía, actitud que la dirigencia central de Al Qaeda consideraba que había demostrado ya sus efectos contraproducentes por restarle apoyo y simpatías en las poblaciones locales. El rompimiento sobrevino en 2014; el ISIL redujo su nombre a Estado Islámico como expresión de sus nuevas pretensiones globales y proclamó un califato que reclamó la obediencia de todos los musulmanes.

La rápida expansión del Estado Islámico por el norte de Iraq y el este de Siria desde mediados de 2014 le granjeó muchas simpatías en la corriente yihadista, lo que favoreció el reclutamiento de jóvenes musulmanes de diversas partes del mundo, incluida Europa, y el reconocimiento de lealtad de varias agrupaciones yihadistas a las que Abu Bakr al-Baghdadi otorgó el título de provincias para recrear simbólicamente la estructura del califato omeya de la época de esplendor de la expansión árabe-islámica. Más allá de las controversias doctrinales, la expansión del Estado Islámico conllevó a su vez la confrontación violenta con $\mathrm{Al}$ Qaeda en diversos escenarios regionales donde ambas contaban con importantes bases de seguidores, sobre todo en Iraq, Siria, Yemen, Sinaí y Libia. Sólo en Túnez, al parecer, la fitna de la corriente yihadista mostró poca beligerancia, debido quizá a la debilidad de los grupos partidarios de cada corriente (Lounnas 2019, 106-107).

Hasta 2016, el Estado Islámico sacó gran ventaja del atractivo de la causa califal y la visibilidad territorial de su poder, factores claves de su vertiginoso ascenso. Pero la dependencia de su autoridad del control de una base territorial constituyó también su principal punto vulnerable. Los ataques aéreos de Estados Unidos y sus aliados occidentales, la intervención militar de Rusia, la exitosa ofensiva de las Fuerzas Democráticas Sirias, y los combates contra casi todo el espectro de fuerzas terrestres del escenario sirio-iraquí, incluidos los grupos salafistas rivales, terminó colapsando la capacidad del Estado Islámico para retener sus bases de poder. A finales de 2017 y 
principios de 2018 cayeron sus últimos reductos importantes, y el califato, como entidad territorial, quedó totalmente derrotado. Desde entonces, Al Qaeda parece haber sacado provecho del descalabro de ISI para robustecer su influencia, especialmente en Siria, donde la Hay'at Tahrir al Sham, heredera del Frente Al-Nusra, logró convertirse en la principal fuerza rebelde en Idlib, el último bastión de la resistencia armada contra el régimen de Bashar al Asad (Humud y Blanchard 2020, 16-17).

Sin embargo, con la derrota territorial del Estado Islámico comenzó también la transformación de la organización en una red descentralizada de células yihadistas. Resulta difícil pronosticar si las rivalidades entre el Estado Islámico y Al Qaeda persistirán por mucho tiempo en esas nuevas circunstancias o si las estrategias de ambas volverán a converger de alguna forma. Lo que parece más evidente es que, con su descomposición y el retorno de muchos militantes a sus lugares de origen, la proliferación de pequeños grupos yihadistas, más difíciles de neutralizar, seguirá constituyendo una seria amenaza para la estabilidad y la seguridad en muchos países de Medio Oriente.

\section{Consideraciones finales}

De lo expuesto hasta aquí, podemos concluir que la inestabilidad de Medio Oriente durante las últimas tres décadas ha estado estrechamente asociada a la progresiva subversión de los precarios equilibrios que soportan el orden regional, ocasionada por las repercusiones de tres coyunturas sucesivas: la abierta por la guerra del Golfo en 1991, la creada por los atentados del 11 de septiembre y la que siguió a la llamada Primavera Árabe en 2011. Cada una marcó de diversas formas el curso de la evolución regional durante una década, cada una tuvo efectos perturbadores sobre la estabilidad regional, y todas ellas fracasaron en el propósito de sentar mejores bases para un reordenamiento viable y duradero en Medio Oriente. 
La guerra del Golfo afectó en grados diferentes los dos pilares sobre los que había descansado la narrativa de la unidad regional hasta ese momento. La supremacía estadounidense propinó el tiro de gracia al maltrecho panarabismo y provocó una ruptura de la unidad islámica que colocó al islamismo radical no sólo en abierta confrontación con Occidente, sino también en contra de los gobiernos de la zona alineados con Estados Unidos. El fin del bipolarismo abrió posibilidades inéditas para un reordenamiento regional con arbitraje estadounidense, pero las prioridades y las preferencias de Washington coadyuvaron a potenciar los desequilibrios. Lejos de impulsar algún proyecto de seguridad colectiva regional, Estados Unidos optó por un clientelismo militar que estimuló la carrera armamentista y contribuyó a fortalecer la capacidad defensiva y represiva de regímenes autoritarios, en particular de las monarquías del Golfo. Asimismo, las negociaciones multilaterales de paz iniciadas en la Conferencia de Madrid fueron claramente disimétricas y, con la excepción del acuerdo jordano-israelí de 1994, dejaron escasos resultados reales; en tanto el proceso de Oslo, desgastado por la tormentosa travesía de casi una década, terminó naufragando en la violencia por el estallido de la intifada y la represión israelí.

Al iniciar el presente siglo persistía una franja geopolíticamente no alineada con Estados Unidos que se extendía desde el Afganistán talibán, al este, hasta los territorios palestinos ocupados por Israel, al oeste, pasando por el gobierno islámico de Irán y los regímenes de Sadam Husein y Bashar al Asad en Iraq y Siria respectivamente. Pero esas realidades, indeseables desde la perspectiva de Washington, no constituían una cadena de eslabones articulados, sino que estaban visiblemente fraccionadas y en algún sentido ejercían contrapesos entre sí: el talibán sunní versus el Irán chií, Iraq versus Irán, o Iraq versus Siria. Pero los atentados del 11 de septiembre cambiaron sensiblemente el escenario debido a la pretensión de la corriente neoconservadora predominante en la Casa Blanca de remo- 
delar políticamente la zona por medio de un agresivo realismo ofensivo.

Las intervenciones militares y las presiones democratizadoras arropadas por la guerra contra el terrorismo contribuyeron a eliminar o socavar los contrapesos existentes, pero no lograron sustituirlos por nuevos equilibrios relativamente estables. Las transiciones políticas promovidas en Afganistán e Iraq, y el Mapa de Ruta concebido para los territorios palestinos, no tuvieron el efecto transformador deseado y naufragaron en una espiral interminable de violencia; mientras que Siria, y sobre todo Irán, sacaron partido de la nueva situación para evitar el aislamiento y proseguir activos dentro del juego geopolítico regional. En vez de erigirse en modelo de estado árabe democrático, Iraq se convirtió en el epicentro de la yihad contra la hegemonía estadounidense, cuyo impacto alcanzó una trascendencia regional incluso mayor que la inspirada antes por la yihad afgana.

La coyuntura de la Primavera Árabe abrió otro ciclo en la erosión del orden regional que, en diversos ámbitos, continúa reflejándose en la actualidad. La amplitud de las protestas populares profundizó en forma inédita la crisis política y social a escala regional, pero la antítesis autoritarismo-democracia quedó pendiente de solución, y con ella también los problemas estructurales y las desigualdades que atizan las contradicciones en el seno de las sociedades contemporáneas de Medio Oriente. Los regímenes autoritarios recurrieron abiertamente a la represión y al empleo de estrategias sectarias para retener el poder y enfrentar los movimientos de protesta, con lo cual el ímpetu democratizador de la sociedad civil quedó finalmente atrapado en el fuego cruzado de la violencia gubernamental y de la oposición radical, y se frustró la esperanza de una transición política por la acción pacífica de los movimientos de masas.

El reflujo democratizador, y la persistencia del autoritarismo y de las condiciones causantes del descontento social, alentaron la acción de las alternativas contestatarias más radi- 
cales, en particular de la violencia sectaria e islamista. En sus expresiones más extremas, la espiral de violencia desencadenó desgarradoras e interminables guerras civiles en Libia, Yemen y Siria, que pronto se convirtieron en cajas de resonancia de la inseguridad regional, en escenarios de la rivalidad de los intereses geopolíticos y en focos de la beligerancia sectaria y yihadista. El conflicto sirio, en particular, vino a potenciar el efecto subversivo generado antes por la crisis iraquí e infligió una fractura demoledora, y quizá irreparable, en el corazón de Medio Oriente, de graves y duraderas consecuencias para el presente y el futuro de la estabilidad regional.

\section{Referencias}

Aвushouk, Ahmed Ibrahim. 2016. "The Arab Spring: A Fourth Wave of Democratization?”. Digest of Middle East Studies 25, núm. 1: 52-69. https://doi.org/10.1111/dome.12080

ACNUR (Alto Comisionado de las Naciones Unidas para los Refugiados). 2019. Global Report 2019. Ginebra: ACNUR. https://reporting. unhcr.org/sites/default/files/gr2019/pdf/GR2019_English_ Full_lowres.pdf\#_ga = 2.8624693.1895802351.1598753516396319858.1598753516

Allison, Roy. 2013. "Russia and Syria: Explaining Alignment with a Regime in Crisis". International Affairs 89, núm. 4: 795-823. https://doi.org/10.1111/1468-2346.12046

Bahgat, Gawdat. 2019. "Iran's Ballistic-Missile and Space Program: An Assessment”. Middle East Policy 26, núm. 1: 31-48. https:// doi.org/10.1111/mepo.12398

Banco Mundial. 2019. Gasto militar (\% del PIB). https://datos. bancomundial.org/indicador/MS.MIL.XPND.GD.ZS?view = chart

Battaloglu, Cihat y Fadi Farasin. 2017. "From Democratization to Securitization: Post-Arab Spring Political Order in the Middle East”. Digest of Middle East Studies 26, núm. 2: 299-319. https:// doi.org/10.1111/dome.12116

BoDANSKY, Yossef. 2001. Bin Laden: el hombre que declaró la guerra a Estados Unidos. México: Aguilar. 
вр World Energy. 2019. вP Statistical Review of World Energy 2019. https://www.bp.com/content/dam/bp/business-sites/en/ global/corporate/pdfs/energy-economics/statistical-review/ bp-stats-review-2019-full-report.pdf

EIA (U.S. Energy Information Administration). 2017. World Oil Transit Chokepoints. https://www.eia.gov/beta/international/ analysis_includes/special_topics/World_Oil_Transit_ Chokepoints/wotc.pdf

Freeman JR., Chas W. 2014. "The Collapse of Order in the Middle East". Middle East Policy 21, núm. 4: 61-68. https://doi. org/10.1111/mepo.12095

FuENTE, Ignacio. 2018. "El terrorismo yihadista en Oriente Medio: Al Qaeda frente al Dáesh”. En Oriente Medio tras el Califato, 195-228. Madrid: Ministerio de Defensa. https://publicaciones. defensa.gob.es/media/downloadable/files/links/c/e/ce_196.pdf Global Firepower. 2020. 2020 Military Strength Ranking. https:// www.globalfirepower.com/countries-listing.asp

Gordon, Philip H., Michael Doran y Jon B. Alterman. 2019. “The Trump Administration's Middle East Policy: A Mid-Term Assessment". Middle East Policy 26, núm. 1: 5-30. https://doi. org/10.1111/mepo.12397

HADDAD, Fanar. 2017. "'Sectarianism' and Its Discontents in the Study of the Middle East”. The Middle East Journal 71, núm. 3: 363-382. https://doi.org/10.3751/71.3.12

HADDAD, Fanar. 2020. Understanding 'Sectarianism'. Sunni-Shi'a Relations in the Modern Arab World. Nueva York: Oxford University Press. https://doi.org/10.1093/oso/9780197510629.001.0001

Humud, Carla E. y Christopher M. Blanchard. 2020. "Armed Conflict in Syria: Overview and U.S. Response”. Congressional Research Service Report RL33487 (27 de julio de 2020). https:// crsreports.congress.gov/product/pdf/RL/RL33487

Humud, Carla E., Jim Zanotti y Clayton Thomas. 2019. “Turkish Incursion into Syria: U.S. Policy Implications”. Congressional Research Service Insight IN11179 (11 de octubre de 2019). https://crsreports.congress.gov/product/pdf/IN/IN11179

JetT, Dennis. 2011. "U.S. Security Assistance in the Middle East: Helping Friends or Creating Enemies?”. Middle East Policy 18, núm. 1: 78-88. https://doi.org/10.1111/j.1475-4967.2011.00474.x 
Kepel, Gilles. 2004. Fitna, guerra en el corazón del islam. Traducido por José Miguel González Marcén. Barcelona: Paidós.

LounNAS, Djallil. 2019. "The Tunisian Jihad: Between al-Qaeda and IsIs". Middle East Policy 26, núm. 1: 97-116. https://doi. org/10.1111/mepo.12403

Makdisi, Ussama Samir. 2000. The Culture of Sectarianism: Community, History, and Violence in Nineteenth-Century Ottoman Lebanon. Berkeley: University of California Press.

Mesa Delmonte, Luis. 2017. "Israel y el conflicto en Siria: de la 'ambigüedad estratégica’ a los ataques militares puntuales”. En Siria en el torbellino: insurrecciones, guerras y geopolítica, coordinado por Gilberto Conde, 275-313. México: El Colegio de México. https://doi.org/10.2307/j.ctt1z27h7q.13

OzTig, Lacin Idil. 2019. "Syria and Turkey: Border-Security Priorities”. Middle East Policy 26, núm. 1: 117-126. https://doi. org/10.1111/mepo.12404

RøRBÆK, Lasse Lykke. 2019. "Religion, Political Power, and the 'Sectarian Surge': Middle Eastern Identity Politics in Comparative Perspective". Studies in Ethnicity and Nationalism 19, núm. 1: 23-40. https://doi.org/10.1111/sena.12292

SIPRI (Stockholm International Peace Research Institute). 2018. SIPRI Yearbook 2018. Armaments, Disarmament and International Security. Oxford: Oxford University Press. https://www.sipri. org/sites/default/files/2018-06/yb_18_summary_en_0.pdf

SIPRI (Stockholm International Peace Research Institute). 2019. SIPRI Yearbook 2019. Armaments, Disarmament and International Security. Oxford: Oxford University Press. http://www.dmrsc. com/Document/SIPRIyearbook2019Summary.pdf

The Soufan Center. 2019. Al-Qaeda in the Indian Subcontinent: The Nucleus of Jihad in South Asia. https://thesoufancenter.org/ wp-content/uploads/2019/01/Al-Qaeda-in-the-Indian-Subcontinent-AQIS.pdf

United States Department of State. 2018. Country Reports on Terrorism 2017. https://www.state.gov/wp-content/uploads/2019/04/ crt_2017.pdf

VALBjøRN, Morten. 2019. "What's so Sectarian about Sectarian Politics? Identity Politics and Authoritarianism in a New Middle East". Studies in Ethnicity and Nationalism 19, núm. 1: 127-149. https://doi.org/10.1111/sena.12289 
Wallin, Mathew. 2018. U.S. Military Bases and Facilities in the Middle East. Washington: American Security Project. https://www. americansecurityproject.org/wp-content/uploads/2018/06/ Ref-0213-US-Military-Bases-and-Facilities-Middle-East.pdf WITS (World Integrated Trade Solution). 2018. Resumen del comercio Irán, Rep. Islámica del 2017. https://wits.worldbank.org/ countrysnapshot/es/IRN

Enrique Baltar Rodríguez es doctor en ciencias históricas por la Universidad de La Habana. De 1983 a 1998 fue profesor de la cátedra de Asia-África del Departamento de Historia General de la Universidad de La Habana y director de ese departamento de 1991 a 1994. Desde 1998 es profesor investigador titular del Departamento de Estudios Políticos e Internacionales de la Universidad de Quintana Roo, donde también desempeñó las responsabilidades de director de la División de Estudios Internacionales y Humanidades (2004-2006) y de secretario general de la universidad (2006-2010). Ha dictado cursos y conferencias sobre su especialidad en diversas universidades del país. Ha sido expositor en más de ochenta congresos nacionales e internacionales y es autor de varios libros y numerosos artículos y capítulos de libros sobre Asia meridional y Medio Oriente. Es miembro del Sistema Nacional de Investigadores del Consejo Nacional de Ciencia y Tecnología, México, y durante el periodo 2011-2017 fue vicepresidente de la Asociación Mexicana de Estudios Internacionales.

https://orcid.org/0000-0003-3404-2412 baltar.rodriguez@gmail.com 